\title{
IDENTIFIKASI GULMA PADA AREAL PERTANAMAN CENGKEH (Eugenia aromatica) DI DESA NALBESSY KECAMATAN LEKSULA KABUPATEN BURU SELATAN
}

\author{
Iskandar Hamid \\ Staf Pengajar Univ. Iqra-Buru, $\boldsymbol{e}$-mail : -
}

\begin{abstract}
ABSTRAK
Kemampuan tanaman bersaing dengan gulma ditentukan oleh spesies gulma, kepadatan gulma, saat dan lama persaingan, cara budidaya dan varietas yang ditanam, serta tingkat kesuburan tanah. Perbedaan spesies akan menentukan kemampuan bersaing karena perbedaan sistem fotosintesis, kondisi perakaran dan keadaan morfologinya. Spesies gulma yang tumbuh cepat, berhabitat besar, dan memiliki metabolisme efisien akan menjadi gulma berbahaya bagi tanaman cengkeh. Persaingan gulma pada awal pertumbuhan akan mengurangi kuantitas hasil, sedangkan persaingan dan gangguan gulma menjelang panen berpengaruh besar terhadap kualitas hasil dari tanaman cengkeh. Perbedaan cara penanaman, laju pertumbuhan dan umur varietas yang ditanam, dan tingkat ketersediaan unsur hara juga akan menentukan besarnya persaingan gulma dan tanaman utama yaitu cengkeh. Prinsip pengendalian gulma pada areal pertanaman cengkeh di Desa Nalbessy Kecamatan Leksula Kabupaten Buru Selatan adalah dengan menekan jumlah populasi gulma sampai ke tingkat yang secara ekonomi tidak merugikan bagi petani cengkeh di Desa Nalbessy. Pengendalian gulma yang dilakukan oleh petani cengkeh di Desa Nalbessy adalah dengan cara, pengendalian secara mekanis dan tradisional yaitu, usaha menekan pertumbuhan gulma dengan cara merusak bagian-bagian gulma sehingga gulma tersebut mati atau pertumbuhannya terhambat
\end{abstract}

Kata Kunci : Nalbessy, gulma, cengkeh

\section{PENDAHULUAN}

\subsection{Latar Belakang}

Memasuki era globalisasi dan perdagangan bebas serta pemberlakuan otonomi daerah, setiap daerah dituntut untuk menggali dan memanfaatkan potensi wilayahnya secara optimal. Kabupaten Buru Selatan mempunyai potensi sumberdaya lahan yang cukup besar khususnya di Desa Nalbessy sehingga perlu mendapatakn perhatian serius dari pemerintah propinsi Maluku. Dengan mencanangkan terwujudnya tatanan masyarakat madani, melalui otonomi daerah dalam format baru Kabupaten Buru Selatan. Hal ini berkonsekuensi langsung terhadap arah dan kebijakan pembangunan daerah yang salah satunya adalah pembangunan sektor pertanian.

Pertanian di Kabupaten Buru Selatan merupakan sektor andalan dalam pembangunan wilayah, dimana sektor ini memberikan kontribusi terbesar terhadap Pendapatan Asli Daerah Kabupaten Buru selatan, serta mampu menyerap tenaga kerja dan tahan terhadap goncangan krisis ekonomi. Oleh karena itu, pembangunan sektor pertanian menjadi prioritas utama dalam pembangunan wilayah Kabupaten Buru Selatan dengan beroreantasi agribisnis, berproduktivitas tinggi, efisien, dan berkelanjutan. Untuk itu diperlukan 
program pembanguan pertanian yang tertata dengan baik, agar lahan produktif dan tidak mengalami kerusakan akibat penggunaan lahan pertanian yang berlebihan.

Suatu agroekosistem yang keanekaragamannya tinggi akan memberi jaminan yang lebih tinggi bagi petani cengkeh. Namun, keanekaragaman tidak selalu mengakibatkan kestabilan, bahkan dapat menyebabkan ketidakstabilan jika komponen-komponennya tidak dipilih dengan baik, misalnya beberapa jenis pohon merupakan inang hama atau penyakit berbahaya bagi tanaman cengkeh sebagai tanaman utama atau pohon bisa bersaing dalam ketenagakerjaan, unsur hara dan air (Dover dan Talbot, 1987). Jika keanekaragaman fungsional bisa dicapai dengan mengkombinasikan spesies tanaman pengganggu atau gulma, yang memiliki sifat saling melengkapi dan berhubungan dalam interaksi sinergetik dan positif, maka bukan hanya kestabilan yang dapat diperbaiki, namun juga produktivitas sistem pertanian dengan input yang lebih rendah.

Komponen agroekosistem juga bisa sinergi dalam fungsinya, misalnya barisan tumbuhan gulma pada garis luar suatu bidang lahan yang mengkonservasi air dan tanah serta memproduksi pakan ternak dan bahan pangan, pagar tanaman di sekitar lahan untuk melindungi dari serangan hewan atau angin sekaligus sebagai penghasil bahan bakar, pangan, pakan hewan atau obat-obatan bagi petani cengkeh.

Pemanfaatan keanekaragaman fungsional sampai pada tingkat yang maksimal mengakibatkan sistem pertanian yang kompleks dan terpadu yang menggunakan sumberdaya dan input yang ada secara optimal. Tantangannya adalah menemukan kombinasi tanaman gulma, dan input yang mengarah pada produktivitas tanaman cengkeh yang tinggi, keamanan produksi serta konservasi sumberdaya yang relatif sesuai dengan keterbatasan lahan, tenaga kerja dan modal yang dimiliki oleh petani di Desa Nalbessy.

Perkembangan pertanian dewasa ini menunjukkan kemajuan yang semakin pesat. Namun bersamaan dengan itu banyak segi yang secara langsung ataupun tak langsung dapat memacu pertumbuhan gulma, seperti penanaman dalam baris, dan jarak tanam yang lebar. Berarti dengan meningkatnya intensifikasi pertanian maka masalah gulma tidaklah semakin ringan, tetapi justru semakin berat. Keadaan suhu yang relatif, cahaya matahari melimpah, dan curah hujan yang cukup di daerah tropik, juga mendorong gulma untuk tumbuh subur. Akibatnya gulma menjadi masalah dalam budidaya di daerah ini.

Dalam perkembangan disiplin gulma modern menurut Soerjani (1988) dalam Sukman dan Yakup (2002), gulma cenderung didefinisikan sebagai tumbuhan yang peranan, potensi dan hakikat kehadirannya belum sepenuhnya diketahui. Sementara itu menurut kenyataan alaminya, relung gulma tidak hanya relung ruang, relung tropik (sumber daya yang diperlukan dan dampak yang dihasilkan), serta relung multidimensional (pengaruhnya terhadap suhu, $\mathrm{pH}$, kelembaban dan sebagainya), tetapi juga relung genetik (perananya sebagai sumber daya genetik).

Gulma diklasifikasikan berdasarkan karakteristik reproduksi, bentuk kehidupan, botani dan lain-lain. Dalam prakteknya terutama untuk kepentingan pengelolaan vegetasi maka klasifikasi botani biasannya digunakan. Menurut klasifikasi ini gulma dibedakan menjadi rumput, teki, dan gulma daun lebar. Berdasarkan bentuk masa pertumbuhan terdiri atas gulma berkayu, gulma air, gulma perambat termasuk epiphytes dan parasit. Ditinjau dari siklus hidupnya dikenal sebagai gulma semusim, dua musim, dan tahunan. Beberapa jenis gulma mungkin termasuk kombinasi dari karakteristik-karakteristik tersebut.

Pertumbuhan gulma dan luas penyebaranya di suatu daerah sangat dipengaruhi oleh keadaan lingkungan 
tempat tumbuh, praktek-praktek bercocok tanam dan juga jenis tanaman perkebunan yang ada. Faktor- faktor lingkungan seperti jenis dan tingkat kesuburan tanah, ketinggian tempat, keadaan air tanah semuanya merupakan faktor -faktor yang sangat penting dan berperan serta dalam membatasi pertumbuhan dan penyebaran gulma.

Komunitas gulma berbeda- beda dari satu tempat ke tempat yang lainnya baik pada jenis pertanaman yang sama maupun yang berbeda. Faktor-faktor yang mempengaruhi sangatlah kompleks dan tidaklah mudah untuk dijelaskan satu persatu. Meskipun demikian, pada umumnya jenis-jenis gulma ini akan beradaptasi pada keadaan lingkungan yang sesuai bagi pertumbuhannya. Keberadaannya pada suatu jenis pertanaman dapat merupakan indikasi adaptasi dan dominasinya di tempat ini akan sangat bergantung pada kondisi lingkungan yang mikro seperti unsur unsur hara yang ada, kelembaban, dan lain-lain. Pada umumnya, jenis-jenis tanaman pertanian semusim akan didominasi oleh jenis-jenis gulma semusim, sedangkaan pada tanaman perkebunan seperti cengkeh yang pada umumnya menahun, jenis-jenis gulma yang mendominasi daerah ini biasanya adalah jenis-jenis gulma yang menahun pula.

Keberadaan gulma pada areal pertanaman budidaya dapat menimbulkan kerugian baik dari segi kuantitas maupun kualitas produksi. Kerugian yang ditimbulkan oleh gulma diantaranya penurunan hasil pertanian akibat persaingan atau kompetisi dalam perolehan sumber daya (air, udara, unsur hara, dan ruang hidup), menjadi inang hama dan penyakit, dapat menyebabkan tanaman keracunan akibat senyawa racun yang dimiliki gulma (alelopati), menyulitkan pekerjaan lapangan dan dalam pengolahan hasil serta dapat merusak atau menghambat penggunaan alat pertanian. Kerugian kerugian tersebut merupakan alasan kuat mengapa gulma harus dikendalikan.
Berdasarkan uraian, dengan melihat dampak negatif atau kerugian yang ditimbulkan gulma pada tanaman cengkeh, maka dilaksanakan penelitian di Desa Nalbessy Kabupaten Buru Selatan untuk mengidentifikasi dan mengenal jenis-jenis gulma pada tanaman cengkeh.

\subsection{Tujuan Penelitian}

Penelitian ini bertujuan untuk :

1. Mengidentifikasi gulma yang terdapat pada areal pertanaman cengkeh di Desa Nalbessy, Kecamatan Leksula Kabupaten Buru Selatan.

2. Mengetahui jenis-jenis gulma yang ada dan banyak dijumpai pada areal pertanaman cengkeh, serta cara pengendaliannya.

\subsection{Kegunaan Penelitian}

Penelitian ini diharapkan dapat bermanfaat sebagai bahan informasi kepada petani dan instansi terkait serta bagaimana cara pengendalian gulma yang tepat, sehingga produksi dari tanaman cengkeh dapat ditingkatkan.

\section{METODE PENELITIAN}

\subsection{Tempat dan Waktu Penelitian}

Penelitian ini dilaksanakan di Desa Nalbessy Kecamatan Leksula Kabupaten Buru Selatan. Kemudian penelitian ini berlangsung selama bulan Desember 2009.

\subsection{Bahan dan Alat}

Bahan dan alat yang digunakan dalam penelitian ini adalah :

Kantong plastik, Karung plastik, Tali rafia, Tali nilon, Amplop kertas, Oven hock, Ukuran suhu, Timbangan analitik, Meteran rol, Pisau, Parang, Gunting, Kamera.

\subsection{Metode Penelitian}

Penelitian ini menggunakan metode survei, dengan cara pengambilan contoh secara proporsif pada areal pertanaman cengkeh di Desa Nalbessy Kecamatan Leksula Kabupaten Buru Selatan. Sampel yang diambil dari jumlah petani cengkeh di Desa Nalbessy, yaitu lahan petani cengkeh 
yang membudidayakan cengkeh secara monokultur dengan luas areal penelitian adalah $1 \mathrm{Ha}$. Dimana blok utama berukuran 15 x $20 \mathrm{~m}$, dengan jumlah 5 petak sampel, yang tersebar secara acak dalam areal pertanaman cengkah.

\subsection{Pelaksanaan Penelitian}

Data yang diambil meliputi data primer dan data sekunder, dimana data sekunder diambil dari kantor desa, dan instansi terkait, sedangkan data primer diperoleh dengan melaksanakan penelitian dilapangan seperti jenis dan populasi gulma yang ada di areal pertanaman cengkeh,

Luas blok yang diamati berukuran $15 \times 20 \mathrm{~m}$, pada areal tanaman cengkeh dimana ukuran petak sampel adalah 1 x 1 $\mathrm{m}$, dengan jumlah 5 petak sampel pada setiap blok pengamatan, jadi jumlah keselurahan petak sampel adalah sebanyak 25 petak sampel dari 5 blok pengamatan yang ada dalam areal pertanaman cengkah tersebut yang ditentukan secara proporsif.

Gulma yang diamati dalam petak sampel dicabut, dihitung populasinya dan diidentifikasi, kemudian dimasukan kedalam kantong plastik yang telah diberikan label sesuai dengan blok pengamatan, untuk dianalisis lebih lanjut. Gulma tersebut ditimbang berat basah maupun berat keringnya, berat kering didapat setelah gulma dikeringkan dengan menggunakan oven, kemudian dikeluarkan lagi untuk ditimbang sampai beratnya konstan. Berat inilah yang dijadikan untuk menentukan jenis gulma yang mendominasi areal pertanaman cengkeh atau biomassa gulma (dominasi gulma).

\subsection{Analisis Data}

Data yang diperoleh dan dikumpulkan dianalisis secara deskriptif yakni memberikan gambaran atau penjelasan (deskripsi) secara rinci, detail dan objektif kemudian disusun dalam bentuk skripsi.

Data mengenai tingkat perkembangan gulma diperoleh melalui hasil pengukuran langsung pada beberapa parameter berikut dengan menghitung frekuensi, populasi serta biomassa gulma, maka digunakan rumus menurut Tjitro Soedirdjo (1984) yaitu :

- Kerapatan Mutlak

$$
\mathrm{K}_{\mathrm{m}}=\Sigma \mathrm{Indv} \text { Jenis dalam Petak contoh }
$$

- Kerapatan Nisbi suatu Jenis $\left(\mathrm{K}_{\mathrm{n}}\right)$

$$
K_{n}=\frac{K_{m i}}{\sum K m} x 100 \%
$$

- Frekuensi Mutlak suatu jenis

$$
F_{m i}=\frac{\sum P_{i}}{\sum P}
$$

- Frekuensi Nisbi suatu jenis

$$
F_{n}=\left(\sum F_{m i}\right) / F_{m}
$$

- Dominasi Mutlak suatu jenis

$$
D_{m}=B k
$$

- Dominasi Nisbi suatu jenis

$$
D_{n}=\frac{D_{m i}}{\sum D_{m}}
$$

Dimana :

Kmi = Kerapatan Mutlak Jenis Tertentu $\mathrm{P}_{\mathrm{i}}=$ Petak contoh yang memuat suatu jenis

$\mathrm{P}=$ Petak contoh

$\mathrm{F}_{\mathrm{mi}}=$ Frekuensi mutlak suatu jenis

$\mathrm{F}_{\mathrm{m}}=$ Frekuensi seluruh jenis spesies gulma

$\mathrm{B}_{\mathrm{k}}=$ Berat kering semua jenis gulma

$\mathrm{D}_{\mathrm{mi}}=$ Dominasi mutlak suatu jenis

$\mathrm{D}_{\mathrm{m}}=$ Dominasi mutlak semua jenis

\section{KEADAAN UMUM LOKASI PENELITIAN}

\subsection{Letak Geografis Dan Administratif}

Letak wilayah yang menjadi tempat penelitian berada di Desa Nalbessy terletak sekitar $4 \mathrm{~km}$ dari ibukota Kecamatan Leksula dan sekitar $22 \mathrm{~km}$ dari ibukota Kabupaten Buru Selatan di Namrole. Luas wilayah penelitian adalah 12.915 ha terdiri dari 1 desa dan 3 lingkungan. Batas administratif wilayah yakni sebelah Selatan berbatasan dengan 
laut Banda, sebelah Utara berbatasan dengan Gunung liang, sebelah Barat berbatasan dengan Kecamatan Leksula dan sebelah Timur berbatasan dengan Desa Kase.

\subsection{Bentuk Topografi}

Wilayah penelitian di Desa Nalbessy mempunyai topografi bervariasi mulai datar, landai, berbukit sampai bergununggunung dengan kemiringan diatas $15 \%$. Ketinggian tempat dari permukaan laut (dpl) berkisar antara $5 \mathrm{~m}$ dpl sampai dengan $600 \mathrm{~m}$ dpl.

\subsection{Keadaan Tanah dan Iklim}

- Jenis dan tekstur tanah juga bervariasi dari jenis tanah alluvial dengan tekstur liat berlempung pasir sampai tanah podsolik merah kuning pada daerah dataran tinggi dengan $\mathrm{pH}$ tanah berkisar antara 5,5 sampai 7,5.

- Wilayah penelitian pada umumnya beriklim tropis dengan curah hujan yang tinggi pada bulan Juni sampai dengan bulan Agustus yang disebut musim hujan. Pada bulan September sampai November rata-rata curah hujan hampir tidak ada yang disebut sebagai musim panas.

- Keadaan suhu udara dipengaruhi oleh curah hujan sehingga pada musim kemarau suhu udara meningkat sampai $35^{\circ} \mathrm{C}$ khususnya pada daerah sekitar pantai dan suhu minimum $25^{\circ} \mathrm{C}$ pada musim hujan. Berbeda untuk daerah dengan ketinggian tempat di atas $100 \mathrm{~m}$ dpl, suhu berkisar antara $27-30^{\circ} \mathrm{C}$.

- Kelembaban udara pada musim hujan rata-rata berkisar antara 45\%-60\% terjadi pada siang hari dan pada malam hari dapat mencapai $70 \%$. Fenomena ini terjadi pada daerah dengan ketinggian di atas $400 \mathrm{~m}$ dpl atau di sekitar Desa Nalbessy

- Wilayah penelitian dipengaruhi angin barat dan timur. Angin barat bertiup dari arah barat ke timur dan umumnya membawa uap air yang ditandai dengan hujan atau tidak terjadi hujan maka kelembaban udara akan meningkat khususnya malam hari. Angin barat biasanya terjadi pada bulan Oktober sampai Februari. Sedangkan angin timur biasanya bertiup dari timur ke barat dan biasanya terjadi pada bulan Juni sampai September.

\section{HASIL PENELITIAN \\ 4.1. Jenis Gulma pada Areal Pertanaman Cengkeh}

Berdasarkan hasil penelitian, maka jenis gulma yang ditemukan pada areal pertanaman cengkeh di Desa Nalbessy sesuai dengan pemahaman kita bahwa setiap jenis tumbuhan berpotensi menjadi gulma. Fryer (1977 cit. Nasution, 1986): Tumbuhan yang berpotensi sebagai gulma cenderung mempunyai ciri khas tertentu yang memungkinkannya untuk mudah tersebar luas dan mampu menimbulkan gangguan dan kerugian. Ciri khas daripada gulma antara lain: pertumbuhannya cepat, mempunyai daya saing yang kuat dalam memperebutkan faktor-faktor kebutuhan hidupnya, mempunyai toleransi yang besar terhadap kondisi lingkungan yang ekstrem, mempunyai daya berkembang biak yang besar secara vegetatif dan atau generatif, alat perkembangbiakannya mudah tersebar melalui angin, air, maupun binatang, dan bijinya mempunyai sifat dormansi yang memungkinkannya untuk bertahan hidup dalam kondisi yang kurang menguntungkan (Nasution, 1986).

Jenis gulma yang ditemukan di areal pertanaman cengkeh di Desa Nalbessy berdasarkan ciri-ciri tersebut adalah Cilorosus aridus (Don) cing (pakis kadal), Hysantes antipoda merr (sawi hutan), Imperata cylindrica L (alang-alang), Stachytarpheta jamaicensis (kakurang), Cyperus iria L. (piso-piso), Chromolaena odorata (L) (sungga-sunga), Eugenia aromatica (anakan cengkeh), Paspalum conjugatum berg (rumput pahit), Leptochloa chinensis (padi-padian), Melastoma malabathricum (babiroro), Eleusine indica (rumput kuda-kuda). 
4.2. Kerapatan, Frekuensi dan Dominasi Nisbi Jenis Gulma

Tabel-abel berikut menggambarkan tentang nilai kerapatan, frakuensi dan dominasi nisbi jenis gulma yang didapat pada lokasi penelitian di Desa Nalbessy Kecamatan Leksula Kabupaten Buru Selatan. Selama bulan Desember 2009.

Tabel 1. Kerapatan Nisbi Janis Gulma Pada Areal Pertanaman Cengkeh (\%)

\begin{tabular}{clllllll}
\hline \multirow{2}{*}{ No } & \multicolumn{1}{c}{ JENIS GULMA } & \multicolumn{1}{c}{ BLOK } & \multirow{2}{*}{ Rata-rata } \\
\cline { 3 - 6 } & & \multicolumn{1}{c}{ B } & C & \multicolumn{1}{c}{ D } & E & \\
\hline 1 & Cilorosus aridus (Don) cing & 28,57 & 30,61 & 40,43 & 30 & 30,62 & 32,05 \\
2 & Hysantes antipoda merr & 8,52 & 24,49 & 10,64 & 14 & 16,33 & 14,81 \\
3 & Imperata cylindrica L. & 14,29 & 16,33 & 14,90 & 14 & 10,21 & 13,95 \\
4 & Stachytarpheta jamaicensis & 14,29 & 8,17 & 10,64 & 6 & 14,29 & 10,68 \\
5 & Cyperus iria L. & 5,71 & 4,09 & 10,64 & 16 & 8,17 & 8,93 \\
6 & Chromolaena odorata (L.) & 8,57 & - & 4,26 & 10 & 16,33 & 7,84 \\
7 & Eugenia aromatica & 20,00 & 6,13 & $8,5-$ & - & - & 6,93 \\
8 & Paspalum conjugatum berg & - & 6,13 & - & 4 & - & 2,03 \\
9 & Leptochloa chinensis & - & 6,13 & - & - & - & 1,23 \\
10 & Melastoma malabathricum & - & - & - & 6 & - & 1,2 \\
11 & Eleusine indica & - & - & - & - & 4,08 & 0,82 \\
\hline
\end{tabular}

Sumber: Data Primer, 2009.

Tabel 2. Frekwensi Nisbi Jenis Gulma Pada Areal Pertanaman Cengkeh (\%)

\begin{tabular}{cllllllll}
\hline \multirow{2}{*}{ No } & \multicolumn{2}{c}{ JENIS GULMA } & \multicolumn{7}{c}{ BLOK } & \multirow{2}{*}{ Rata-rata } \\
\cline { 3 - 6 } & & \multicolumn{1}{c}{$\mathbf{A}$} & $\mathbf{C}$ & \multicolumn{1}{c}{$\mathbf{D}$} & $\mathbf{E}$ & \\
\hline 1 & Cilorosus aridus (Don) cing & 27,27 & 29,41 & 30,77 & 26,67 & 26,67 & 28,16 \\
2 & Hysantes antipoda merr & 9,09 & 23,53 & 15,39 & 13,34 & 20 & 16,87 \\
3 & Imperata cylindrica L & 9,09 & 17,65 & 15,39 & 13,34 & 6,67 & 12,43 \\
4 & Stachytarpheta jamaicensis & 18,18 & 5,89 & 15,39 & 6,67 & 13,34 & 11,90 \\
5 & Chromolaena odorata (L) & 9,09 & - & 7,69 & 13,34 & 20 & 10,03 \\
6 & Cyperus iria L & 9,09 & 5,89 & 7,69 & 13,34 & 6,67 & 8,54 \\
7 & Eugenia aromatica & 18,18 & 5,89 & 7,69 & - & - & 6,37 \\
8 & Paspalum conjugatum berg & - & 5,89 & - & 6,67 & - & 2,52 \\
9 & Melastoma malabathricum & - & - & - & 6,62 & - & 1,34 \\
10 & Eleusine indica & - & - & - & & 6,67 & 1,34 \\
11 & Leptochloa chinensis & - & 5,89 & - & - & - & 1,18 \\
\hline
\end{tabular}

Sumber : Data Primer, 2009.

Tabel 3. Dominasi Nisbi Jenis Gulma Pada Areal Pertananm Cengkeh (\%)

\begin{tabular}{|c|c|c|c|c|c|c|c|}
\hline \multirow[b]{2}{*}{ No } & \multirow{2}{*}{ JENIS GULMA } & \multicolumn{5}{|c|}{ PETAK CONTOH } & \multirow{2}{*}{ Rata-rata } \\
\hline & & A & B & C & D & $E$ & \\
\hline 1 & Cilorosus aridus (Don) cing & 24,19 & 19,62 & 36,67 & 38,71 & 17,20 & 27,32 \\
\hline 2 & Stachytarpheta jamaicensis & 23,34 & 33,54 & 17,10 & 16,94 & 26,55 & 23,40 \\
\hline 3 & Chromolaena odorata (L) & 36,80 & - & 9,12 & - & 30,56 & 15,30 \\
\hline 4 & Hysantes antipoda merr & 3,15 & 28,22 & 12,22 & 12,47 & 11,87 & 13,59 \\
\hline 5 & Imperata cylindrica $L$ & 10,09 & 14,55 & 14,00 & 8,92 & 6,08 & 10,73 \\
\hline 6 & Cyperus iria L & 2,10 & 0,53 & 1,14 & 9,25 & 3,46 & 3,30 \\
\hline 7 & Melastoma malabathricum & & & & 12,15 & - & 2,43 \\
\hline 8 & Eugenia aromatica & 0,32 & 1,06 & 9,35 & - & - & 2,17 \\
\hline 9 & Eleusine indica & & & & 1,51 & 4,30 & 1,17 \\
\hline 10 & Paspalum conjugatum berg & & 1,60 & & - & - & 0,32 \\
\hline 11 & Leptochloa chinensis & & 0,98 & & - & - & 0,20 \\
\hline
\end{tabular}




\section{PEMBAHASAN}

\subsection{Karakteristik Sistem Budidaya Tanaman Cengkeh}

Karakteristik sistem budidaya tanaman cengkeh pada lahan milik petani cengkeh di Desa Nalbessy yang menjadi objek penelitian di lapangan disajikan pada Tabel 4.

Vegetasi lain dalam areal pertanaman cengkeh turut menunjang suhu, dan kelembaban yang terbentuk dalam areal tersebut, dimana gulma membutuhkan suhu yang lebih rendah, kelembaban yang tinggi dan sinar matahari yang tidak terlalu banyak. Hal ini terbukti dengan ditemukannya jenis gulma Cilorosus aridus (Don) cing dengan kerapatan, frekuensi dan dominasi nisbi yang tertinggi. Selain itu kehadiran vegetasi lain dalam areal pertanaman cengkeh itu sendiri, dalam hal bersaing untuk mendapatkan cahaya matahari, unsur hara, oksigen dan karbondioksida dari dalam lingkungan areal pertanaman cengkeh. Persaingan inipun akan mempengaruhi ketahanan tanaman cengkeh dengan gulma sehingga, semakin tinggi ketahanan tanaman cengkeh maka semakin kuat tanaman cengkeh untuk bersaing dengan gulma.

Tabel 5. Karakteristik Budidaya Tanaman Cengkeh Pada Areal Pertanaman di Desa Nalbessy Kecamatan Leksula Kabupaten Buru Selatan.

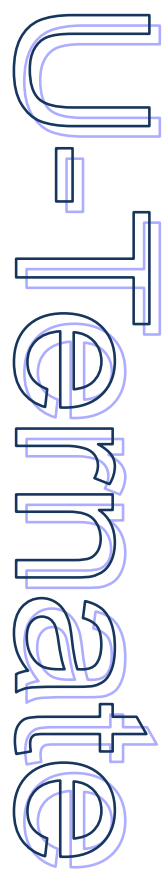

\subsection{Kerapatan Nisbi Jenis Gulma}

Dari hasil penelitian yang dilakukan dapat dijalaskan bahwa rata-rata kerapatan nisbi tertinggi pada areal pertanaman cengkeh di Desa Nalbessy, Kecamatan Leksula Kabupaten Buru Selatan adalah gulma Cilorosus aridus (Don) cing $(32,05 \%)$, sedangkan kerapatan nisbi terendah adalah jenis gulma Eleusine indica $(0,82 \%)$. Hal ini disebabkan karena faktor lingkungan di desa Nalbessy lebih menunjang untuk berkembeng biak terutama dengan rimpang dan spora dari gulma Cilorosus aridus (Don) cing serta mampu tumbuh dan berkembang dengan baik di tempat yang terbuka maupun tempat yang terlindung. Kemudian faktor lain yang menyebabkan gulma Cilorosus aridus (Don) cing tumbuh dan berkembang dengan cepat di desa Nalbessy adalah gulma Cilorosus aridus (Don) cing tidak disukai oleh ternak untuk dijadikan sebagai makanannya sehingga keberadaannya selalu dalam kondisi stabil bila dibandingkan dengan gulma Hysantes antipoda merr $(14,81 \%)$, Imperata cylindrica L. (13,95\%), Stachytarpheta jamaicensis $(10,68 \%)$, Cyperus iria $L$. $(8,93 \%)$, Chromolaena odorata (L.) $(7,84 \%)$, Eugenia aromatica (6,93\%), Paspalum conjugatum berg (2.03\%), Leptochloa chinensis (1,23\%), Melastoma malabathricum (1,2\%), Eleusine indica $(0.82 \%)$. Dengan demikian kerapatan nisbi jenis gulma Cilorosus aridus (Don) cing lebih banyak mendominasi areal pertanaman cengkeh di desa Nalbessy dan mampu tumbuh dan berkembang biak dengan baik, bila dibandingkan dengan jenis-jenis gulma yang lainnya.

Faktor lain yang mempengaruhi kerapatan nisbi gulma Cilorosus aridus (Don) cing yang semakin tinggi karena gulma mampu berkompetisi dengan tanaman cengkeh dalam hal perebutan unsur hara dari tanah, air, karbondioksida, dan oksigen, serta cahaya matahari dan ruang tumbuh di bandingkan dengan jenisjenis gulma yang ada lainnya. Dalam Fryer dan mutzanaka (1988), bahwa kehadiran 
suatu jenis gulma pada awal pertanaman secara luas dipengaruhi oleh tanaman budidaya dalam hal ini cengkeh dalam menyaingi gulma tersebut. Dan tinggi rendahnya kerapatan nisbi suatu jenis gulma ditentukan oleh mampu tidaknya gulma itu bersaing dengan tanaman cengkeh.

\subsection{Frekuensi Nisbi Jenis Gulma}

Kita ketahui bahwa gulma dapat berkembangbiak secara generatif yaitu dengan biji dan spora, dan juga secara vegetatif dengan stolon, yaitu batang menjalar di permukaan tanah, pada setiap buku/ ruas dapat tumbuh tunas dan akar menjadi individu baru. Dan dengan rimpang yaitu batang menjalar dalam tanah, pada setiap buku/ruas dapat tumbuh tunas dan akar menjadi individu baru. Menurut Tanasale dan Goo (2007), alat perkembangbiakan gulma menentukan luasnya penyebaran gulma. Bila faktor eksternal lingkungan mendukung bagi perkembangan biji maupun spora dari gulma maka gulma akan berkembang dan tumbuh dengan baik.

Untuk rata-rata frekuensi nisbi tertinggi jenis gulma pada areral pertanaman cengkeh di Desa Nalbessy, kecamatan Leksula Kabupaten Buru Selatan adalah gulma Cilorosus aridus (Don) cing $(28,16 \%)$, sedangkan rata-rata frekuensi nisbi terendah adalah Leptochloa chinensis $(1,18 \%)$. Hal ini disebabkan karena spora (sari) yang dimiliki oleh gulma Cilorosus aridus (Don) cing tersebut mudah tersebar dengan bantuan angin dari suatu tempat ketempat lain, dan pada saat jatuh ketanah, kelembaban dan suhu serta kondisi lingkungan yang sangat menunjang spora atau sarinya untuk lebih mudah tumbuh dan berkembang serta akar rimpang yang menjalar dengan cepat di dalam tanah yang mampu tumbuh dengan cepat dengan kondisi tanah yang tersedia unsur haranya bila dibandingkan dengan jenis gulma Hysantes antipoda merr (16,87\%), Imperata cylindrica $L$. $(12,43 \%)$, Stachytarpheta jamaicensis
(11,90\%), Cyperus iria L. (8,54\%), Chromolaena odorata (L.) (10,03\%), Eugenia aromatica (6,37\%), Paspalum conjugatum berg (2,52\%), Leptochloa chinensis (1,18\%), Melastoma malabathricum (1,34\%), Eleusine indica (1.34\%). Dengan demikian jenis gulma yang sering ditemukan pada areal pertanaman cengkeh di Desa Nalbessy adalah gulma Cilorosus aridus (Don) cing (pakis kadal) atau jenis paku-pakuan.

\subsection{Dominasi Nisbi Jenis Gulma}

Dominasi nisbi suatu jenis gulma ditentukan oleh tinggi rendahnya gulma tersebut, lebar daun, diameter batang dan panjang akar. Untuk rata-rata dominasi nisbi tertinggi jenis gulma pada areal pertanaman cengkeh di desa Nalbessy adalah jenis gulma Cilorosus aridus (Don) cing (27,32\%), sedangkan dominasi nisbi terendah adalah Leptochloa chinensis $(0,20 \%)$. Hal ini disebabkan karena Cilorosus aridus (Don) cing lebih sering ditemukan dalam areal penelitian dengan tingkat kerapatan nisbi tertinggi yaitu $(32,05 \%)$, serta tingkat frekuensi nisbi tertinggi yaitu $(28,16 \%)$, dan jenis gulma Cilorosus aridus (Don) cing pada umumnya berukuran lebih tinggi $(33,65 \mathrm{~cm})$, sehingga sangat jelas dominasi (berat kering) akan lebih tinggi bila dibandingkan dengan jenis gulma Hysantes antipoda merr (13,59\%), Imperata cylindrica L. (10,73\%), Stachytarpheta jamaicensis (23,40\%), Cyperus iria $L$. (3,30\%), Chromolaena odorata $(L)$ $(15,30 \%)$, Eugenia aromatica $(2,17 \%)$, Paspalum conjugatum berg (0,32\%), Leptochloa chinensis (0,20\%), Melastoma malabathricum (4,43\%), Eleusine indica $(1.17 \%)$. Dengan melihat dominasi nisbi jenis gulma dapat dijelaskan bahwa faktor utama yang menyebabkan rendah dominasi gulma pada areal pertanaman cengkeh di Desa Nalbessy disebabkan karena gulma tersebut tidak mampu bersaing dengan tanaman utama dalam hal perebutan unsur hara dan sinar matahari serta kondisi alam dan faktor lingkungannya. 


\subsection{Teknik Pengendalian Gulma pada Areal Pertanaman Cengkeh}

Prinsip pengendalian gulma pada areal pertanaman cengkeh di Desa Nalbessy Kecamatan Leksula Kabupaten Buru Selatan adalah dengan menekan jumlah populasi gulma sampai ke tingkat yang secara ekonomi tidak merugikan bagi petani cengkeh di Desa Nalbessy. Memulihkan semua gulma secara tuntas biasanya hanya dilakukan jika gulma amat merugikan, dan itupun pada tempat-tempat yang terbatas yaitu pada areal pertanaman cengkeh. Ada beberapa metode untuk mengurangi populasi gulma diantaranya pengendalian secara preventif, pengendalian mekanik, pengendalian kultur teknis, pengendalian hayati (biologis) dan pengendalian kimiawi (Sukman dan Yakup, 2002).

Namun secara umum pengendalian gulma yang dilakukan oleh petani cengkeh di desa Nalbessy adalah dengan cara, pengendalian secara mekanis yaitu, usaha menekan pertumbuhan gulma dengan cara merusak bagian-bagian gulma sehingga gulma tersebut mati atau pertumbuhannya terhambat. Teknik pengendalian ini hanya mengandalkan kekuatan fisik atau mekanik. Dalam praktek dilakukan secara tradisional dengan tangan, alat sederhana, dan tata cara pengendalian gulma secara mekanis dapat dilakukan dengan cara pembabatan, menginjak-injak gulma, pencangkulan tanah terutama untuk lahan kering, yang biasanya dilakukan dengan alat seperti parang, sabit, dan cangkul.

Setiap aspek teknik budidaya secara langsung atau tidak langsung dapat mengurangi atau menekan pertumbuhan gulma. Cara pengendalian gulma secara kultur teknis yang dapat dilakukan yaitu dengan cara pengolahan tanah dan pengaturan jarak tanam, sehingga keberadaan gulma sebisa mungkin dikendalikan oleh petani cengkeh di Desa Nalbessy yang pada akhirnya dapat meningkatkan produktifitas tanaman cengkeh dan kesejahteraan bagi petani di desa Nalbessy.

\section{KESIMPULAN DAN SARAN}

\subsection{Kesimpulan}

- Rata-rata kerapatan nisbi tertinggi pada areal pertanaman cengkeh di Desa Nalbessy, Kecamatan Leksula kabupaten Buru Selatan adalah gulma Cilorosus aridus (Don) cing (32,05\%), sedangkan kerapatan nisbi terendah adalah jenis gulma Eleusine indica $(0,82 \%)$.

- Untuk rata-rata frekuensi nisbi tertinggi jenis gulma pada areral pertanaman cengkeh di Desa Nalbessy, Kecamatan Leksula Kabupaten Buru Selatan adalah gulma Cilorosus aridus (Don) cing $(28,16 \%)$, sedangkan rata-rata frekuensi nisbi terendah adalah Leptochloa chinensis (1,18\%).

- Rata-rata dominasi nisbi tertinggi jenis gulma pada areal pertanaman cengkeh di Desa Nalbessy adalah jenis gulma Cilorosus aridus (Don) cing (27,32\%), sedangkan dominasi nisbi terendah adalah Leptochloa chinensis $(0,20 \%)$.

- Pengendalian gulma yang dilakukan oleh petani cengkeh di Desa Nalbessy adalah dengan cara, pengendalian secara mekanis dan tradisional yaitu, usaha menekan pertumbuhan gulma dengan cara merusak bagian-bagian gulma sehingga gulma tersebut mati atau pertumbuhannya terhambat.

\subsection{Saran}

Diperlukan peran serta pemerintah daerah dalam hal ini pemerintah Kabupaten Buru Selatan untuk memberikan penyuluhan dan pemahaman khususnya kepada masyarakat petani cengkeh bahwa kehadiran gulma pada areal pertanaman cengkeh perlu dikendalikan, untuk itu harus adanya kerja sama yang baik dari pemerintah daerah dalam hal pemberian bantuan mesin pemotong rumput sehingga permasalahan gulma dapat diatasi. 


\section{DAFTAR PUSTAKA}

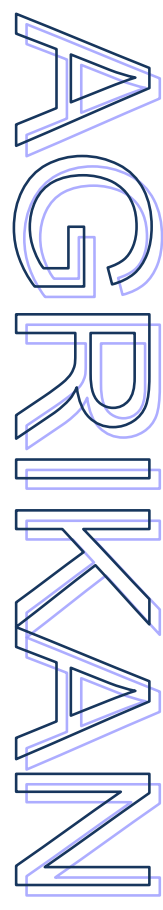

Anonim, 2010, Budi Daya Cengkeh Dimaksimalkan (online)

http://www.wawasandigital.com/index.php?option=com_content\&task=view\&id $=35232 \&$ Itemid $=53$ (Diakses Januari 2010)

Anonim, 2010, Budidaya Cengkeh (Online)

http://www.naturalnusantara.co.id/indek_3_3_3.php?id=52 (Diakses Januari 2010)

Anonim, 2010, Klasifikasi Gulma (Online)

http://pertanian.blogdetik.com/2009/02/28/klasifikasi-gulma/ (Diakses Januari 2010)

Anonim, 2010, Identifikasi Gulma-Gulma Dominan Pada Pertanaman Padi Sawah http://cetlanget.wordpress.com/2009/07/12/identifikasi-gulma-gulmadominan-pada-pertanaman-padi-sawah/ (Diakses Januari 2010)

Anonim, 2010, Peranan Gulma Dalam Pengelolaan Lingkungan http://ejournal.unud.ac.id/abstrak/peranan\%20gulma.pdf (Diakses Januari 2010)

Anonim, 2010, Pengendalian Gulma di Lahan Pasang Surut (Online) http://www.pustaka-deptan.go.id/agritek/isdp0102.pdf (Diakses Januari 2010) Anonim, 2010, GULMA (Online) http://gotomilla.blogspot.com/2009/03/gulma.html (Diakses Januari 2010)

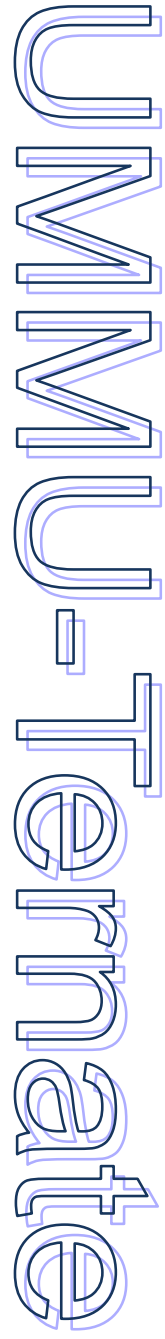
Anonim, 2010, Inventarisasi Gulma Di Bawah Tegakan Pulai Darat http://www.dephut.go.id/files/Sri_Utami.pdf (Diakses Januari 2010)

Arief, A, 1992. Perlindungan Tanaman, Hama Penyakit Dan Gulma, Penerbit Usaha Nasional, Surabaya

Jumin,H,B, 2002. Agronomi, PT Raja Grafindo Persada, Jakarta

Moenandir, J, 1993. Pengantar Ilmu dan Pengendalian Gulma, Rajawali Pers, Jakarta

Moenandir, J, 1993. Persaingan Tanaman Budidaya Dengan Gulma, Rajawali Pers, Jakarta

Moenandir, J, 1993. Ilmu Gulma Dalam Sistem Pertanian, Rajawali Pers, Jakarta.

Rukmana, R dan Saputra, S. 2003. Gulma Dan Teknik Pengendaliannya, Penerbit Kanisius, Yokyakarta

Sukman, Y, Dan Yakup, 2002. Gulma dan Teknik Pengendaliannya, Fakultas Pertanian Universitas Sriwijaya Palembang, Palembang.

Sastroutomo S, S, 1990, Ekologi Gulma, PT Gramedia Pustaka Utama, Jakarta.

Setijati, S, 1980. Rumput Dataran Rendah, Lembaga Biologi Nasional, LIPI, Bogor 